\title{
Aberrant splicing of the hRasGRP4 transcript and decreased levels of this signaling protein in the peripheral blood mononuclear cells in a subset of patients with rheumatoid arthritis
}

Toko Hashimoto, Shinsuke Yasuda*, Hideyuki Koide, Hiroshi Kataoka, Tetsuya Horita, Tatsuya Atsumi and Takao Koike

\begin{abstract}
Introduction: An unidentified population of peripheral blood mononuclear cells (PBMCs) express Ras guanine nucleotide releasing protein 4 (RasGRP4). The aim of our study was to identify the cells in human blood that express hRasGRP4, and then to determine if hRasGRP4 was altered in any patient with rheumatoid arthritis (RA).

Methods: Monocytes and T cells were purified from PBMCs of normal individuals, and were evaluated for their expression of RasGRP4 mRNA/protein. The levels of RasGRP4 transcripts were evaluated in the PBMCs from healthy volunteers and RA patients by real-time quantitative PCR. The nucleotide sequences of RasGRP4 CDNAs were also determined. RasGRP4 protein expression in PBMCs/monocytes was evaluated. Recombinant hRasGRP4 was expressed in mammalian cells.
\end{abstract}

Results: Circulating CD14 ${ }^{+}$cells in normal individuals were found to express hRasGRP4. The levels of the hRasGRP4 transcript were significantly higher in the PBMCs of our RA patients relative to healthy individuals. Sequence analysis of hRasGRP4 CDNAs from these PBMCs revealed 10 novel splice variants. Aberrantly spliced hRasGRP4 transcripts were more frequent in the RA patients than in normal individuals. The presence of one of these abnormal splice variants was linked to RA. The levels of hRasGRP4 protein in PBMCs tended to be lower. As expected, the defective transcripts led to altered and/or nonfunctional protein in terms of P44/42 mitogenactivated protein (MAP) kinase activation.

Conclusions: The identification of defective isoforms of hRasGRP4 transcripts in the PBMCs of RA patients raises the possibility that dysregulated expression of hRasGRP4 in developing monocytes plays a pathogenic role in a subset of RA patients.

\section{Introduction}

Ras guanine nucleotide releasing protein (RasGRP) 4 is a calcium-regulated guanine nucleotide exchange factor (GEF) and diacylglycerol (DAG)/phorbol ester receptor. The mouse, rat and human cDNAs and genes that encode this signaling protein were initially cloned during a search for novel transcripts selectively expressed in mast cells (MCs) by Yang and coworkers [1-3]. Others isolated a hRasGRP4 cDNA while searching for

\footnotetext{
* Correspondence: syasuda@med.hokudai.ac.jp

Department of Medicine II, Hokkaido University Graduate School of Medicine, North 15, West 7, Kita-ku, Sapporo, 060-8638, Japan
}

transcripts that encode oncogenic proteins in a patient with acute myeloid leukemia [4]. Mouse and human RasGRP4 mRNAs are abundant in an undefined population of peripheral blood mononuclear cells (PBMCs) [1,3]. Although all examined mature MCs in the tissues of normal humans and mice express RasGRP4 [1-3], it remains to be determined whether this signaling protein is expressed in another cell type.

Different isoforms of mouse, rat and human RasGRP4 $[1,2,5]$ and its family member RasGRP1 have been identified which in each instance are caused by variable splicing of their precursor transcripts. For example, the lag

\section{( Biomed Central}


mouse develops a lymphoproliferative disorder that resembles systemic lupus erythematosus (SLE) due to a failure to properly process the precursor mRasGRP1 transcript [6]. In support of these mouse data, we identified a subset of SLE patients that lacks the normal isoform of hRasGRP1 in their circulating $\mathrm{T}$ cells and PBMCs [7]. Splice variants of the hRasGRP4 transcript have been detected in the PBMCs of a limited number of patients with mastocytosis and asthma, as well as the HMC-1 cell line established from a patient with MC leukemia [1]. These data raised the possibility of altered expression of hRasGRP4 in some disease states.

RasGRP4 regulates the expression of many genes in the HMC-1 line, including the transcripts that encode prostaglandin $\mathrm{D}_{2}$ synthase, the transcription factor GATA-1, and the interleukin (IL)-13 inhibitory receptor IL13R $\alpha 2[5,8]$. In support of these in vitro data, the mature RasGRP4 ${ }^{+} \mathrm{MCs}$ that reside in the peritoneal cavity of mice and rats preferentially metabolize arachidonic acid to prostaglandin $\mathrm{D}_{2}$ [9] due to their high levels prostaglandin $\mathrm{D}_{2}$ synthase [10].

Rheumatoid arthritis (RA) is a chronic inflammatory disease characterized by a distinctive synovitis resulting in progressive joint destruction. Although several genetic predispositions and environmental factors are known to increase the risk of developing RA, its pathogenesis is not completely understood $[11,12]$. MCs have been implicated in RA and experimental models of this autoimmune disorder. Tissue specimens isolated from the joints of RA patients contain increased numbers of hTryptase- $\beta^{+}$MCs, and these effecter cells tend to localize at the junction of the pannus and cartilage, as well as in areas where the pannus is invading cortical bone [13-15]. MC-deficient $\mathrm{WBB}_{1} \mathrm{~F}_{1}-\mathrm{Kit}^{\mathrm{W}} / \mathrm{Kit}^{\mathrm{W}-\mathrm{v}}$ and $\mathrm{WCB} \mathrm{F}_{1}-\mathrm{Kitl}^{\mathrm{Sl}} / \mathrm{Kitl}^{\mathrm{Sl}-\mathrm{d}}$ mice are resistant to arthritis induced by autoantibodies against collagen, glucose-6phosphate isomerase, or methylated bovine serum albumin (BSA) [16-19]. Activated MCs produce a diverse array of proinflammatory factors, including varied granule serine proteases. In the $\mathrm{K} / \mathrm{BxN}$ mouse serum-transfer [20] and methylated BSA/IL-1 [19] arthritis models, MC-restricted tryptase heparin complexes regulate the accumulation of neutrophils and the loss of aggrecan proteoglycans in the cartilage.

MCs, monocytes, and macrophages originate from a common progenitor in humans [21], and hTryptase- $\beta^{+}$ MCs can be generated from human cord blood and PBMCs [22]. Circulating myeloid cells also differentiate into tissue-resident macrophage and dendritic cells. Macrophages are abundant in the RA synovium. Upon activation, these immune cells release substantial amounts of inflammatory cytokines and growth factors (for example, IL-1 $\beta$, IL-6, tumor necrosis factor- $\alpha$ (TNF- $\alpha$ ) and transforming growth factor- $\beta$ ) that participate in synovial inflammation and hyperplasia [23-25]. Thus, MCs and myeloid cells play pivotal roles in the pathophysiology of RA.

In the present study, we discovered that the $\mathrm{CD} 14^{+}$ myeloid cells in human PBMCs express hRasGRP4. As dysregulation of hRasGRP1 occurs in a subset of patients with SLE [7], we hypothesized that hRasGRP4 might be abnormally expressed in the PBMCs that give rise to MCs, macrophages, and possibly other cell types in some patients with RA. We now report that abnormal splicing of the hRasGRP4 transcript is frequent in the PBMCs of RA patients. The accumulated data raise the possibility that altered expression of hRasGRP4 occurs in a subset of RA patients.

\section{Materials and methods}

\section{Healthy individuals and patients with RA and other} autoimmune disorders

Forty-two apparently healthy Japanese individuals (6 males and 36 females, $49.8 \pm 6.7$ years old, mean \pm SD) and 57 Japanese patients with RA (16 males and 41 females, $61.1 \pm 13.5$ years old, mean \pm SD) were studied. All patients in the latter cohort were diagnosed as having RA by rheumatologists based on the American College of Rheumatology 1987 revised criteria for the classification of this autoimmune disease [26]. The mean disease duration of our RA patients was 126 months (range $=0$ to 504 months). The Disease Activity Score in 28 joints (DAS28ESR4) [27] at the time of analysis was $3.3 \pm 1.3$ (range $=1.3$ to 6.8 ). Fifty-one $(89 \%$ ) of these patients were receiving anti-rheumatic drugs. Thirty-seven (65\%), 13 (27\%), 7 (12\%), and 39 (68\%) of these patients were on methotrexate, sulphasalazine, bucillamine and prednisolone, respectively. Three patients were on biological agents. Thirty-six patients with other autoimmune diseases served as autoimmune controls. The patients in this control group had SLE ( $n$ $=10)$, polymyositis/dermatomyositis $(n=8)$, systemic sclerosis $(n=8)$, or the Sjögren's syndrome $(n=10)$. Our study was approved by the Human Ethics Committee of Hokkaido University Graduate School of Medicine, and informed consent was obtained from each subject.

\section{Cell separation}

PBMCs were collected from approximately $10 \mathrm{ml}$ of the peripheral blood drawn from healthy individuals or patients using Ficoll paque PLUS (Amersham Biosciences, Uppsala, Sweden). CD $14^{+}$cells were purified from the resulting PBMCs using micro beads and a magnetic cell sorting separation unit (Miltenyi Biotec, Bergisch Gladbach, Germany). CD14, CD3, and CD19 micro beads were used to enrich non-monocyte, non- $T$ cell, and non-B cells in the PBMCs by negative 
selection. This fraction is supposed to contain undifferentiated cells including mast cell progenitors [28]. T cells were also purified from the PBMCs using the RosetteSep human $\mathrm{T}$-cell enrichment cocktail (StemCell Technology, Vancouver, BC, Canada). The purities of the obtained cells were routinely $>85 \%$ for $\mathrm{CD} 14^{+}$myeloid cells and $>95 \%$ for $\mathrm{CD}^{+} \mathrm{T}$ cells, as assessed on a FACS Calibur flow cytometer (BD Biosciences, San Jose, CA, USA) using phycoerythrin-labeled anti-CD14 and anti-CD3 antibody (BD Biosciences), respectively.

\section{Evaluation of hRasGRP4 transcript levels, and isolation of novel hRasGRP4 transcripts in RA patients}

Total RNA was collected from whole PBMCs and separated cells using RNeasy Mini kits (Qiagen, Valencia, CA, USA). The obtained transcripts were converted into cDNAs employing QuantiTect Reverse Transcription kits (Qiagen). The coding regions of the hRasGRP4 cDNAs were then amplified by a PCR method using the forward 5'-AGCATGAACAGAAAAGACAGTAAG-3' and the reverse 5'-TGTCTAGGAATCCGGCTTGGA-3' primers which correspond to nucleotide sequences residing at the translation-initiation and -termination sites in the normal hRasGRP4 transcript noted at GenBank accession number [NM:170604], respectively. After a heat-denaturation step, each of the 25 cycles of the subsequent PCR steps consisted of a 15-s denaturing step at $94^{\circ} \mathrm{C}$, a 30 -s annealing step at $59^{\circ} \mathrm{C}$, and a 1.5 minute extension step at $72^{\circ} \mathrm{C}$. The transcript that encodes the housekeeping protein human glyceraldehyde-3-phosphate dehydrogenase (hGAPDH) served as a control in these transcript analyses.

A real-time quantitative PCR (qPCR) approach was used to monitor the overall levels of the hRasGRP4 transcripts in fractionated cell lineages and in PBMCs from 38 healthy individuals, 41 patients with RA, and 36 patients with other rheumatic diseases. In these experiments, the level of the hRasGRP4 transcript was normalized to that of the hGAPDH transcript using an ABI Prism 7000 Sequence Detection System (Applied Biosystems, Foster City, CA, USA) and TaqMan MGB probes specific for hRasGRP4 (Hs00364781m1) and hGAPDH (Hs00266705m1) (Applied Biosystems). We chose a hRasGRP4-specific primer set in these qPCRs that recognizes the junction nucleotide sequence located between exons 7 and 8. Relative quantification was performed using the comparable cycle threshold $\left(\mathrm{C}_{\mathrm{T}}\right)$ method in which $\Delta \mathrm{C}_{\mathrm{T}}$ is the level of the hRasGRP4 transcript in the RNA sample relative to that of the hGAPDH transcript. The difference in the expression of the hRasGRP4 transcripts among each sample was defined as fold changes in mRNA levels by $2^{-\Delta \Delta C T}$.

The nucleotide sequences of 295 hRasGRP4 transcripts were also determined using RNA isolated from
16 healthy individuals, 23 patients with RA (18 under treatment and 5 untreated), and 20 patients with other autoimmune diseases ( 5 with SLE, 5 with Sjögren's syndrome, 5 with inflammatory myositis and 5 with systemic sclerosis. In each instance, the generated hRasGRP4 cDNAs were subcloned into pcDNA3.1 V5His-TOPO (Invitrogen, Carlsbad, CA, USA), and five arbitrarily selected cDNAs from each individual were sequenced using an ABI Prism 3130 Genetic Analyzer (Applied Biosystems).

\section{Evaluation of hRasGRP4 transcript levels in macrophages and osteoclasts}

Macrophages were differentiated from peripheral blood CD $14^{+}$cells in the presence of several cytokines using previously reported technology [29]. Briefly, macrophages were obtained by culturing $\mathrm{CD} 14^{+}$cells in the presence of M-CSF (50 ng/ml). After seven days incubation at $37^{\circ} \mathrm{C}$ in a humid chamber, differentiated cells were collected. Osteoclasts were differentiated in the presence of M-CSF (33 ng/ml) and RANK-ligand (66 $\mathrm{ng} / \mathrm{ml}$ ) (Lonza Walkersville, Inc., Walkersville, MD, USA). After 14 days, cells were collected. RNA was collected from each cell lineage and hRasGRP4 expression was examined for both cell lineages using TaqMan MGB probes specific for hRasGRP4 and hGAPDH. Expression of cathepsin- $K$, one of the specific markers for differentiated osteoclasts, was evaluated for osteoclasts to confirm their differentiation (Probe ID: Hs00166156m1) (Applied Biosystems)[30]. RasGRP1 expression was also examined in the PBMC and in osteoclasts (Probe ID: Hs00996734m1) (Applied Biosystems).

\section{Use of an anti-peptide approach to obtain antibodies that recognize the $\mathrm{N}$ terminus of hRasGRP4}

Rabbit anti-hRasGRP4 antibodies were generated against the novel 14-mer synthetic peptide MNRKDSKRKSHQEC that corresponds to the N terminus of the normal isoform of hRasGRP4. A Basic Local Alignment Search Tool (BLAST) protein search revealed no similar sequence in any other known human protein. Using this synthetic peptide, rabbit polyclonal antihRasGRP4 antibodies were generated and purified, as previously described for the generation of rabbit antihRasGRP1 antibodies [7]. The specificity of the generated anti-hRasGRP4 antibodies was confirmed by absorption assay using the same peptide as used for immunization both in immunoblot and in immunohistochemistry using lysates of epithelial cell line HEK-293 (line CRL-1573; American Type Culture Collection) transfected with expression constructs encoding hRasGRP4 with the C-terminal V5 epitope tag (data not shown). 
Generation of recombinant hRasGRP4 proteins using mammalian cell line and cell-free transcription-translation assay

Expression constructs encoding hRasGRP4 and its splice variants (variant 5 and 6) were transfected into the epithelial cell line HEK-293 that normally lacks hRasGRP4. The cDNAs that encode normal RasGRP4 and its splice variants were subcloned into pcDNA3.1 V5-His-TOPO (Invitrogen). We made hRasGRP4 constructs with or without C-terminal V5 tag. Transfections were performed using Lipofectamine 2000 Reagent (Invitrogen). The presence of the RasGRP4 at the protein level was evaluated by a SDS-PAGE immunoblot and by immunohistochemistry. A cell-free transcription: translation assay was performed using the PROTEINscript II T7 kit (Ambion, Austen, TX, USA) according to the manufacturer's instruction. Constructs encoding full-length normal RasGRP4, splice variant 5 and splice variant 6 were subjected to the system and evaluated by immunoblotting.

\section{Immunohistochemistry}

Immunohistochemistry was carried out on PBMCderived $\mathrm{CD}_{14}{ }^{+}$myeloid cells and $\mathrm{T}$ cells, and hRasGRP4-expressing HEK293 cells. Non-transfected HEK293 cells were used as negative control. A total of 500,000 cells in each instance were placed on a glass slide using a Shandon Cytospin 4 Cytocentrifuge (Thermo Fisher Scientific Inc., Waltham, MA, USA). hRasGRP4 ${ }^{+}$HEK293 cells were cultured on a Lab-Tek II Chamber Slide System (Nalge Nunc International, Rochester, NY, USA). The prepared slides were fixed and permeabilized with $4 \%$ paraformaldehyde and $0.2 \%$ saponin (eBioscience, San Diego, CA, USA). Endogenous peroxide was quenched using a $3 \%$ solution of hydrogen peroxide in absolute methanol; blocking was done with a $3 \%$ solution of BSA in phosphate-buffered saline. Immunohistochemistry was performed using our rabbit anti-hRasGRP4 antibodies $(1 \mu \mathrm{g} / \mathrm{ml})$ or rabbit anti- $\beta$ actin antiserum (Sigma-Aldrich, St. Louis, MO, USA) diluted 1:80, followed by the relevant biotinylated antibodies and peroxidase-conjugated streptavidin (Nichirei Biosciences, Tokyo, Japan). Irrelevant rabbit IgG served as another negative control for our anti-hRasGRP4 antibodies. An absorption staining procedure was performed using a cocktail mixture of our anti-hRasGRP4 antibodies $(1 \mu \mathrm{g} / \mathrm{ml})$ and synthetic hRasGRP4-derived peptide $(100 \mathrm{ng} / \mathrm{ml})$. The immunoreaction was visualized using a $0.6 \%$ hydrogen peroxide (Nichirei Biosciences) solution containing 3,3'-diaminobenzidine tetrahydrochloride (DAB). Nuclear staining was done with hematoxylin, and the resulting stained cells were examined by light microscopy.

\section{Immunoblotting}

After conjugation of our anti-hRasGRP4 antibodies with horse-radish peroxidase using Lightning-link HRP conjugation kit (Innova Biosciences, Cambridge, UK), the levels of hRasGRP4 protein in $\mathrm{CD}_{14}{ }^{+}$peripheral blood cells were evaluated using an immunoblot approach, as previously described [7]. Densities of immune-reactive bands were measured using ImageJ software supported by NIH [31]. Anti-phospho-P44/42 mitogen-activated protein kinase (MAPK) (Erk1/2) antibodies and antipan-P44/42 MAPK antibodies were purchased from Cell Signaling Technologies (Beverly, MA, USA).

\section{Statistical analysis}

The chi-square test or Fisher's exact test was used to compare the frequencies of the identified hRasGRP4 variants in our patient's PBMCs. To evaluate the expression of a specific hRasGRP4 isoform, we first defined the normal range of $\Delta \Delta$-CT value as the mean $\pm 2 \mathrm{SD}$ of the healthy volunteers. The levels of the hRasGRP4 transcript in the RA patients were then quantitated. The expression of hRasGRP4 transcripts in control individuals and patients were compared using Fisher's exact test. The incidence of splice variants and expression levels of this gene were compared by using Mann-Whitney's U-test. In all of the statistical analyses, JMP version 9.0 software (SAS Institute Inc., Cary, NC, USA) was utilized.

\section{Results}

Identification of hRasGRP4 mRNA and protein isoforms in CD14 ${ }^{+}$myeloid cells

Circulating in vivo-differentiated, unfractionated human PBMCs and PBMC-derived $\mathrm{CD}^{+}{ }^{+} \mathrm{T}$ cells, $\mathrm{CD} 14^{+}$myeloid cells, and $\mathrm{CD} 14^{-} / \mathrm{CD}^{-} / \mathrm{CD} 19^{-}$cells were initially evaluated for the presence of hRasGRP4 mRNA using a semi-quantitative reverse transcriptase-PCR approach. Employing primers that correspond to the start and end of the protein's coding domain, the approximately 1.5$\mathrm{kb}$ cDNA that encodes the normal isoform of hRasGRP4 was found to be abundant in the circulating $\mathrm{CD} 14^{+}$cells present in the PBMCs of normal individuals (Figure 1A), as previously found [1]. The presence of large amounts of hRasGRP4 mRNA in these cells was confirmed by a real-time qPCR approach using different primers (Figure $1 \mathrm{~B}$ ). The non- $\mathrm{T}$, non- $\mathrm{B}$, non-monocyte population of $\mathrm{CD}^{-} 4^{-} / \mathrm{CD}^{-} / \mathrm{CD}^{-} 9^{-}$cells in these PBMCs contained relatively lower amounts of hRasGRP4 mRNA, and the level of the hRasGRP4 transcript was below detection in enriched peripheral blood $\mathrm{T}$ cells. In agreement with these transcript data, the $\mathrm{CD} 14^{+}$cells purified from in vivo-differentiated human PBMCs contained hRasGRP4 protein as assessed immunohistochemically (Figure 1C). As expected, immunoreactive 


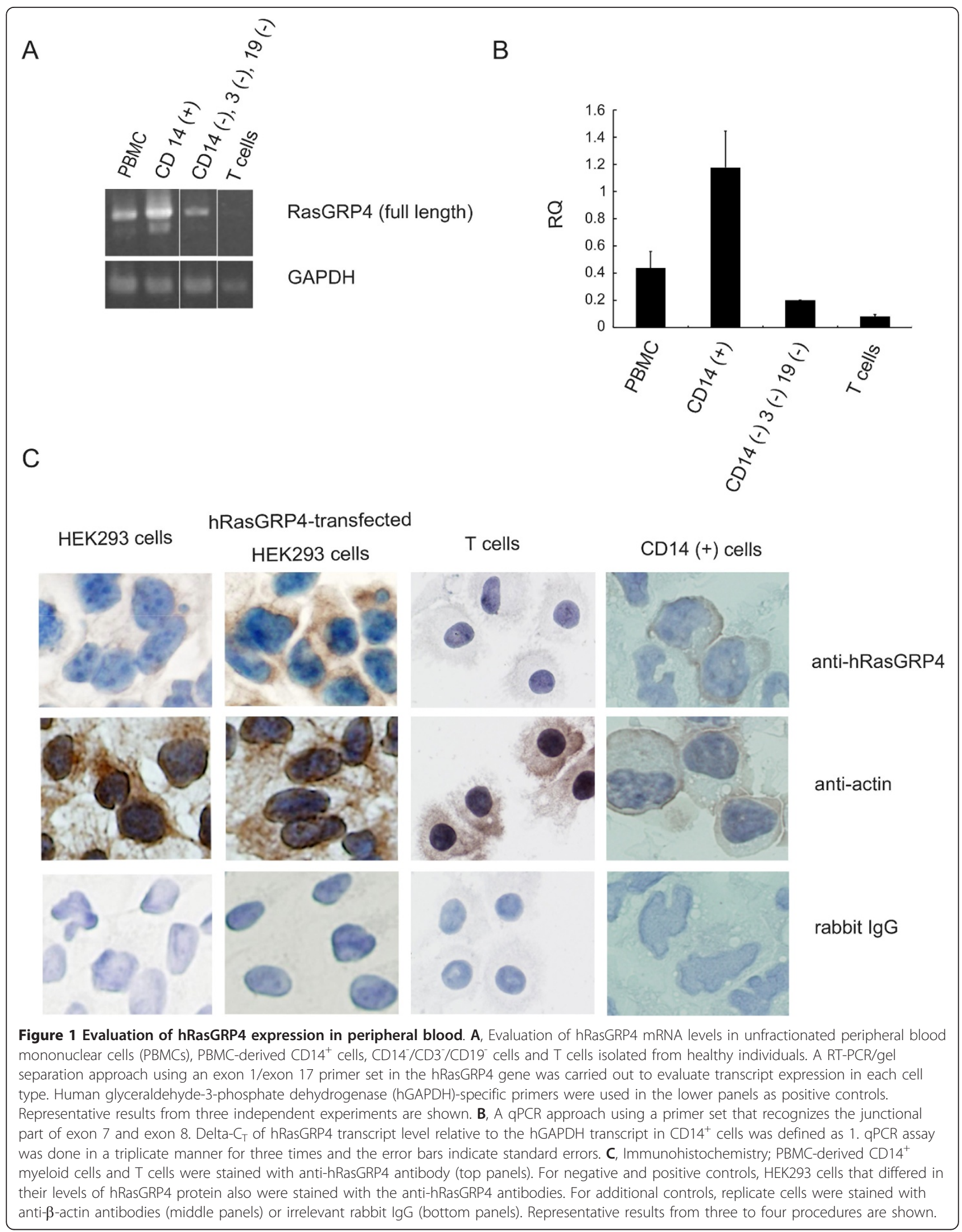


hRasGRP4 protein was not detected in T cells. Transfected HEK293 cells that differed in their levels of hRasGRP4 served as positive and negative controls.

\section{hRasGRP4 transcript levels during $\mathrm{CD} 14^{+}$cell} development into macrophages and osteoclasts

hRasGRP4 transcript levels decreased while $\mathrm{CD} 14^{+}$peripheral blood cells differentiated into macrophages (Additional file 1/Figure s1A). RasGRP4 expression was diminished in osteoclasts (Additional file 1/Figure s1B, left panel), which was not countered at least by RasGRP1 (data not shown). Development of multinucleated osteoclasts was confirmed by light microscope. Elevated Cathepsin K expression was confirmed in these cells (Additional file 1/Figure s1B, right panel).

\section{Quantitative evaluation of hRasGRP4 transcripts in} patients with RA and other autoimmune diseases

We designated normal levels of hRasGRP4 transcripts in PBMCs as the mean $\pm 2 \mathrm{SD}$ of that in the PBMCs of healthy individuals. The levels of the hRasGRP4 transcripts were higher than the normal levels in $41 \%$ of our RA patients $(P<0.0001)$ (Figure 2$)$. The levels of the hRasGRP4 transcript also were higher in the PBMCs of patients that had other autoimmune diseases: $\operatorname{SLE}(P=$ $0.0009)$, polymyositis/dermatomyositis $(P=0.02)$, systemic sclerosis $(P=0.006)$, and Sjögren's syndrome $(P=$ $0.0004)$. Thus, the presence of increased amounts of hRasGRP4 mRNA in PBMCs appears to be a useful marker for the identification of patients with autoimmune disorders. Despite these data, the levels of the hRasGRP4 transcript in the PBMCs of our RA patients was not correlated with the examined clinical features (for example, age, disease duration, DAS28, erythrocyte sedimentation rate (ESR), or serum matrix metalloproteinase 3 (MMP3)) (data not shown). Also in healthy individuals, RasGRP4 expression levels were not affected by age (data not shown). In addition, the levels of hRasGRP4 transcript were not affected by the ratios of monocytes in the PBMCs (represented by the sum

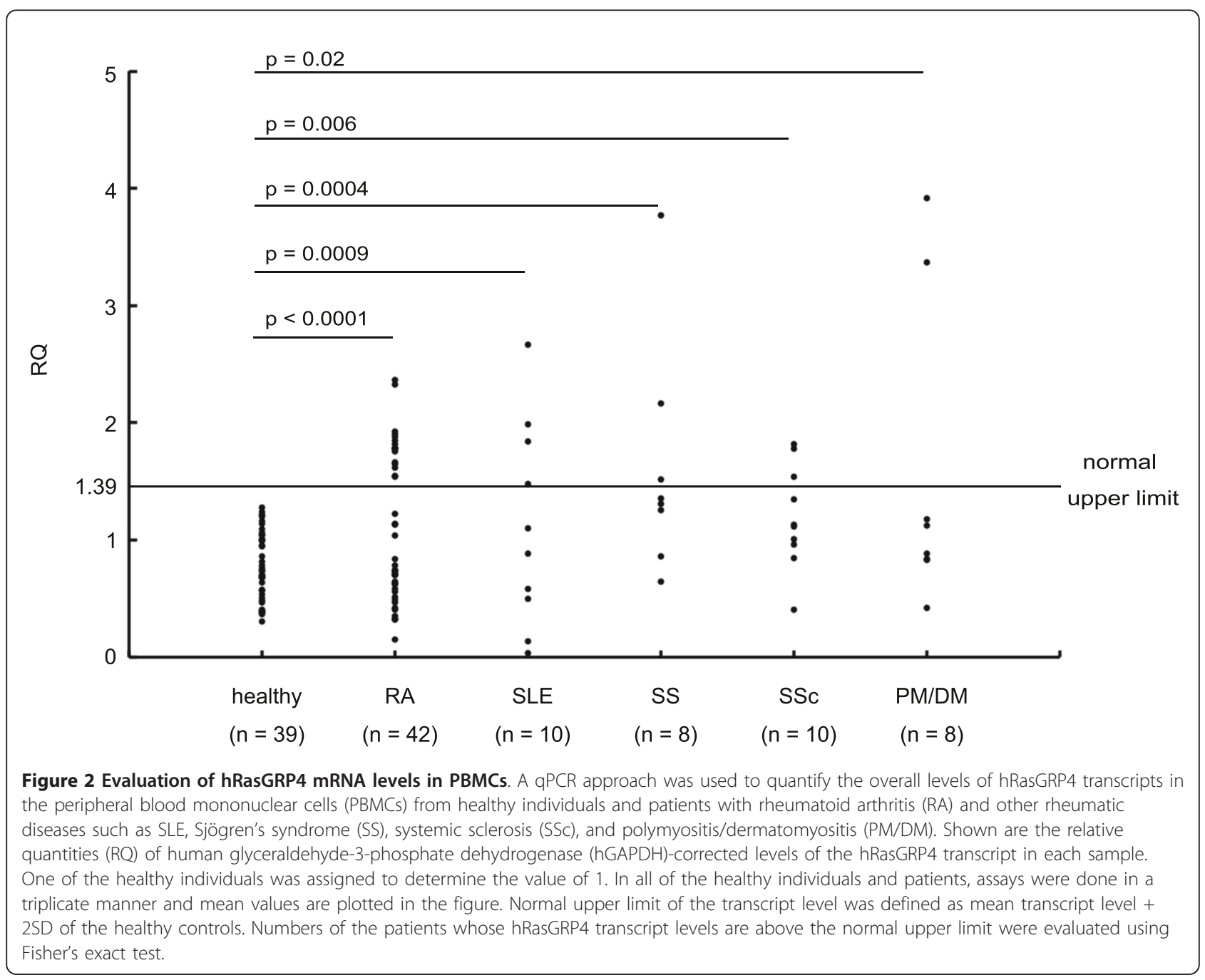


number of lymphocytes and monocytes) from our RA patients (Additional file 2/Figure s2). Therefore, it would be acceptable for a screening to evaluate hRasGRP4 transcript levels using PBMC instead of using purified monocytes.

\section{Identification of 10 novel hRasGRP4 transcripts that have} undergone defective splicing of the precursor transcript Sequence analysis of the hRasGRP4 cDNAs from 16 healthy individuals and $23 \mathrm{RA}$ patients (including 5 patients on no therapy) revealed 12 isoforms of hRasGRP4 caused by alternative splicing of its precursor transcript (Figure 3). Four previously identified isoforms of hRasGRP4 have been designated as splice variants 1 to 4 [1]. Two of the alternative splicing isoforms identified in our RA patients correspond to variants 1 and 2. However, the other 10 isoforms (designated as variants 5 to14) have not been previously described. These novel splice variants that lack the entire exon 9 (splice variant 5, GenBank accession number: (FJ768677)); the first 207 nucleotides of exon 9 (splice variant 6, GenBank accession number: (FJ768678)); exon 7 (splice variant 7, GenBank accession number: (FJ768679)); exons 7, 8, and 9 (splice variant 8, GenBank accession number: (FJ768680]); exons 7 and 8 (splice variant 10, GenBank accession number: (FJ768682)); exon 6 (splice variant 11); and 12 nucleic acids at the 5 ' end of exon 12 (splice variant 13). Intron 14 had not been removed in splice variant 9 (GenBank accession number: (FJ768681)); 143 nucleotides from intron 11 had not been removed in splice variant 12; and 143 nucleotides from intron 11 and 95 nucleotides from intron 14 had not been removed from splice variant 14 .

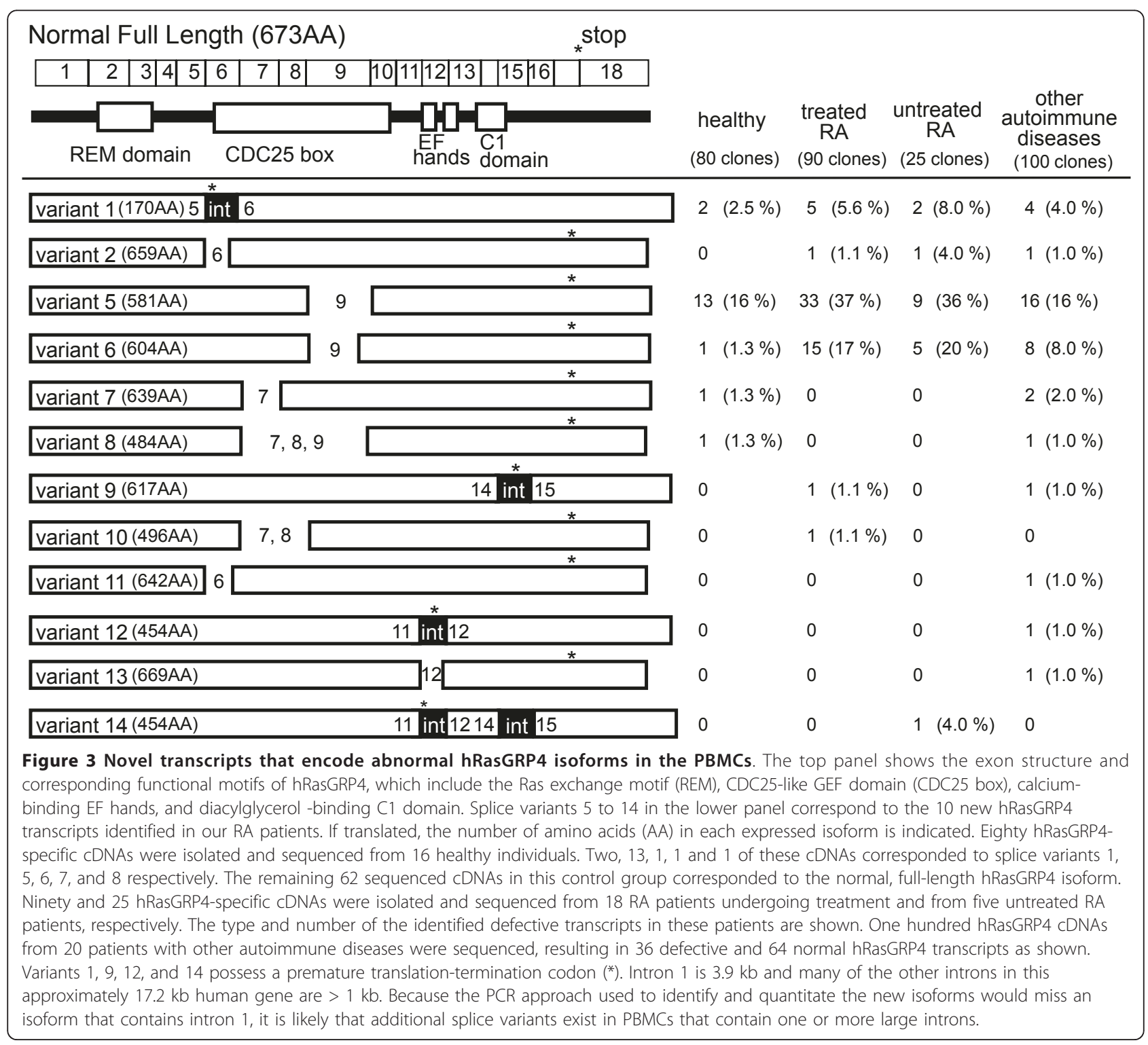


The most frequently found abnormal hRasGRP4 transcript identified in our group of RA patients was splice variant 5, which lacks the entire exon 9. Loss of this exon does not cause a frame-shift abnormality or a premature translation-termination codon in the processed transcript but does results in the loss of 92 amino acids which correspond to the C-terminal half of the CDC25like catalytic domain in the signaling protein [1]. The second most frequent isoform was variant 6 which results in the loss of 69 of these same amino acids. Splice variants 9,12 , and 14 are more severely altered isoforms because they create in each instance a premature translation-termination codon. The hRasGRP4 splice variants as well as splice variant 6 were more frequent in clone number in the PBMCs of our RA patients (Table 1 ). Twenty clones corresponding to splice variant 6 from our RA patients were not from a few patients that express multiple clones of this variant. The distribution of splice variant 6 was one clone from eight RA patients and two clones from six RA patients. None of our RA patients had more than half of splice variant 6 from the sequenced clones. Except for splice variant 6 , the frequencies of these splice variants were not significantly different in the PBMCs of patients with other autoimmune diseases relative to that of healthy subjects. Splice variant 6 was scarcely detected in the PBMCs of normal individuals. In healthy subjects, frequency of RasGRP4 splice variants was not related to their age (data not shown). In RA patients, the presence

Table 1 Statistical analysis of hRasGRP4 isoforms in healthy subjects and patients with RA and autoimmune controls

\begin{tabular}{|c|c|c|c|c|c|}
\hline & normal & $\begin{array}{l}\text { variant } \\
(\%)\end{array}$ & OR & $95 \% \mathrm{Cl}$ & $P$-value \\
\hline \multicolumn{6}{|l|}{ Any variant } \\
\hline Healthy subjects & 62 & $18(22.5)$ & & & \\
\hline RA patients (total) & 47 & $74(67.3)$ & 5.42 & $\begin{array}{l}2.86 \text { to } \\
10.3\end{array}$ & 0.00000016 \\
\hline $\begin{array}{l}\text { RA patients } \\
\text { (untreated) }\end{array}$ & 9 & $16(64.0)$ & 6.12 & $\begin{array}{l}2.32 \text { to } \\
16.2\end{array}$ & 0.00029 \\
\hline \multirow[t]{2}{*}{$\begin{array}{l}\text { Autoimmune } \\
\text { controls }\end{array}$} & 69 & $31(31.0)$ & 1.55 & $\begin{array}{l}0.79 \text { to } \\
3.04\end{array}$ & 0.27 \\
\hline & $\begin{array}{l}\text { non- } \\
\text { variant } 6\end{array}$ & $\begin{array}{l}\text { variant } \\
6\end{array}$ & OR & 95\% C.I. & $P$-value \\
\hline \multicolumn{6}{|l|}{ Variant 6} \\
\hline Healthy subjects & 79 & $1(1.3)$ & & & \\
\hline RA patients & 95 & $20(18.0)$ & 16.6 & $\begin{array}{l}2.18 \text { to } \\
126\end{array}$ & 0.00035 \\
\hline $\begin{array}{l}\text { Autoimmune } \\
\text { controls }\end{array}$ & 92 & $8(8.0)$ & 6.87 & $\begin{array}{l}0.84 \text { to } \\
56.1\end{array}$ & 0.038 \\
\hline
\end{tabular}

$\mathrm{Cl}$, confidential interval and $P$-values were calculated by Chi-square test to evaluate the incidence of alternative splicing with healthy subjects and patients groups. The frequency of variant 6 in each group was evaluated by Fisher's exact probability test. The percentage (\%) of sequenced clones that contained an aberrant hRasGRP4 transcript is also indicated. OR, odds ratio; $\mathrm{RA}$, rheumatoid arthritis of splice variant 6 was not related to any evaluated clinical features (that is, age, disease activity, serum MMP3 levels, disease duration, or therapy treatment) (Table 2). However, this specific variant was more frequent in our male RA patients. The levels of hRasGRP4 transcripts evaluated by real-time qPCR were significantly high in individuals who possess splice variant $6(P=0.02$, calculated using Mann-Whitney's U-test). Because abnormal splicing of RasGRP4 was most evident in patients with RA, we focused on RasGRP4 expression in RA patients in the following study.

\section{hRasGRP4 protein levels in the PBMCs and CD14 ${ }^{+}$ peripheral blood cells isolated from healthy individuals and RA patients}

The levels of hRasGRP4 protein were lower in the PBMCs from many of our RA patients relative to that of healthy control individuals (Figure 4A). Abnormal-sized bands corresponding to splice variant 5 or 6 were scarcely detected by our immunoblot analysis, except that patients 1 and 2 had detectable smaller-sized bands. Although there remains a possibility that our antibodies do not recognize alternatively-spliced isoforms, recombinant hRasGRP4 splice variant 6 with C-terminal V5 tag was recognized clearly by our anti-hRasGRP4 antibodies and by anti-V 5 antibody (data not shown). Most of our RA patients express abnormal isoforms of the hRasGRP4 transcript from simultaneously obtained samples (Table 3). The levels of hRasGRP4 protein in CD14 ${ }^{+}$peripheral blood cells were also lower in RA patients compared to those in healthy individuals (Figure 4B).

\section{Recombinant hRasGRP4 protein using cell-free} transcription-translation assay and mammalian cell line Full-length hRasGRP4, splice variant 5 and splice variant 6 were expressed at protein levels at expected sizes in a cell-free transcription-translation assay (Figure 5A). Similar protein expression was observed in mammalian

Table 2 Comparison of the clinical features between RA patients with hRasGRP4 variant 6 and those without

\begin{tabular}{llll}
\hline & variant 6 (-) & variant 6 (+) & P-value \\
\hline Age (years) & $62.6 \pm 6.2$ & $61.4 \pm 11.2$ & $0.96^{*}$ \\
Male/female & $0 / 10$ & $6 / 7$ & $0.012^{\dagger}$ \\
DAS28(ESR4) & $3.8 \pm 1.2$ & $3.4 \pm 1.85$ & $0.31^{*}$ \\
MMP-3 & $307 \pm 127$ & $148 \pm 109$ & 0.057 \\
Disease duration (months) & $100(0$ to 492) & $143(0$ to 504) & $0.58^{*}$ \\
\{mean (range) & & & \\
Patients on therapy & 4 & 8 & $0.77^{\dagger}$ \\
Patients on no therapy & 2 & 3 & \\
\hline
\end{tabular}

The $P$-values in the first four rows $\left(^{*}\right)$ were calculated using Mann-Whitney's $U$-test; the $P$-values $\left({ }^{\dagger}\right)$ were calculated by chi-square test with Yates' correction. DAS28, The Disease Activity Score in 28 joints; MMP, matrix metalloproteinase; $R A$, rheumatoid arthritis 


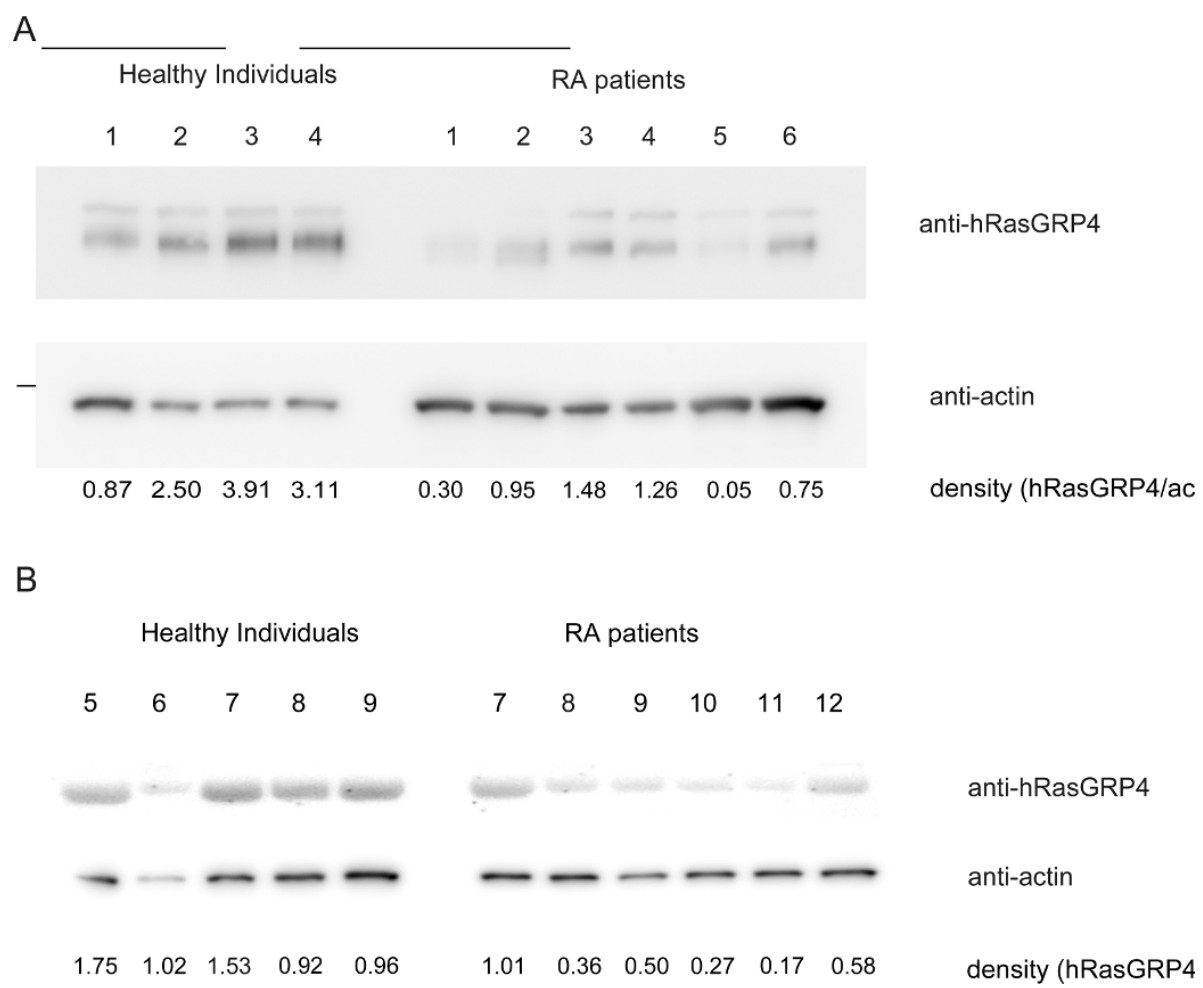

Figure 4 Protein expression of hRasGRP4 in the peripheral blood evaluated by immunoblotting. A. Immunoblotting of peripheral blood mononuclear cells from patients with RA and healthy controls. Lysates were prepared from peripheral blood mononuclear cells from patients with rheumatoid arthritis (RA) and healthy controls. Approximately $3 \mu \mathrm{g}$ of protein from each lysate was subjected to SDS-PAGE. Immunoblotting was performed using peroxidase-conjugated anti-hRasGRP4 antibodies and anti- $\beta$-actin antibodies. PBMCs from four healthy individuals and six RA patients were evaluated in panels A. B. Immunoblotting of circulating CD14 ${ }^{+}$cells isolated from five healthy controls and six RA patients.

cell-transfection system (Figure 5B, left panel). After transfection with full-length RasGRP4 into HEK293 cells, P44/42 MAP kinase activation naturally occurred, when compared to non-transfected cells (Figure 5B, right panel). Whereas, transfection with splice variant 6 barely activated P44/42 MAPK. Thus, as expected, hRasGRP4 splice variant 6 was functionally defective for the activation of Ras-Erk pathway.

Table 3 Clinical profiles and sequenced hRasGRP4 CDNAs of the patients and healthy controls whose peripheral blood samples were obtained simultaneously as those in Figure 4A

\begin{tabular}{|c|c|c|c|c|c|c|c|c|c|}
\hline & Age & Sex & DAS28 & Treatment & Clone 1 & Clone 2 & Clone 3 & Clone 4 & Clone 5 \\
\hline Healthy 1 & 32 & $\mathrm{~F}$ & 0 & none & $\mathrm{FL}$ & $\mathrm{FL}$ & Variant 5 & $\mathrm{FL}$ & $\mathrm{FL}$ \\
\hline Healthy 2 & 31 & $\mathrm{~F}$ & 0 & none & $\mathrm{FL}$ & $\mathrm{FL}$ & Variant 5 & Variant 6 & $\mathrm{FL}$ \\
\hline Healthy 3 & 38 & $F$ & 0 & none & $\mathrm{FL}$ & $\mathrm{FL}$ & Variant 7 & $\mathrm{FL}$ & $\mathrm{FL}$ \\
\hline Healthy 4 & 38 & F & 0 & none & $\mathrm{FL}$ & $\mathrm{FL}$ & $\mathrm{FL}$ & $\mathrm{FL}$ & \\
\hline RA 1 & 70 & M & 3.22 & $\begin{array}{l}\text { MTX } 8 \mathrm{mg} / \text { week } \\
+ \text { IFX }\end{array}$ & $\mathrm{FL}$ & $\mathrm{FL}$ & $\mathrm{FL}$ & Variant 6 & $\mathrm{FL}$ \\
\hline RA 2 & 66 & F & 3.82 & MTX 6 mg/week & $\mathrm{FL}$ & $\mathrm{FL}$ & $\mathrm{FL}$ & Variant 6 & Variant 2 \\
\hline RA 3 & 61 & F & 2.17 & $\begin{array}{l}\text { MTX } 10.5 \text { mg/week } \\
+ \text { TAC } 3 \text { mg/day }\end{array}$ & Variant 5 & Variant 5 & Variant 5 & Variant 5 & Variant 5 \\
\hline RA 4 & 33 & $F$ & 4.87 & $\begin{array}{l}\text { MTX } 8 \text { mg/week } \\
+ \text { PSL } 5 \text { mg/day }\end{array}$ & Variant 5 & $\mathrm{FL}$ & Variant 5 & $\mathrm{FL}$ & Variant 5 \\
\hline RA 5 & 78 & M & 2.65 & $\begin{array}{l}\text { MTX } 6 \text { mg/week } \\
+ \text { SSZ } 1000 \text { mg/day }\end{array}$ & $\mathrm{FL}$ & Variant6 & Variant 5 & Variant 5 & Variant 6 \\
\hline RA 6 & 53 & $F$ & 2.27 & $\begin{array}{l}\text { MTX } 10 \text { mg/week } \\
+ \text { PSL } 2 \text { mg/day }\end{array}$ & Variant 5 & Variant 5 & Variant 5 & Variant 5 & Variant 5 \\
\hline
\end{tabular}

DAS28, The Disease Activity Score in 28 joints; FL, full-length; IFX, infliximab; MTX, methotrexate; PSL, prednisolone; RA, rheumatoid arthritis; SSZ, sulphasalazine; TAC, tacrolimus. 


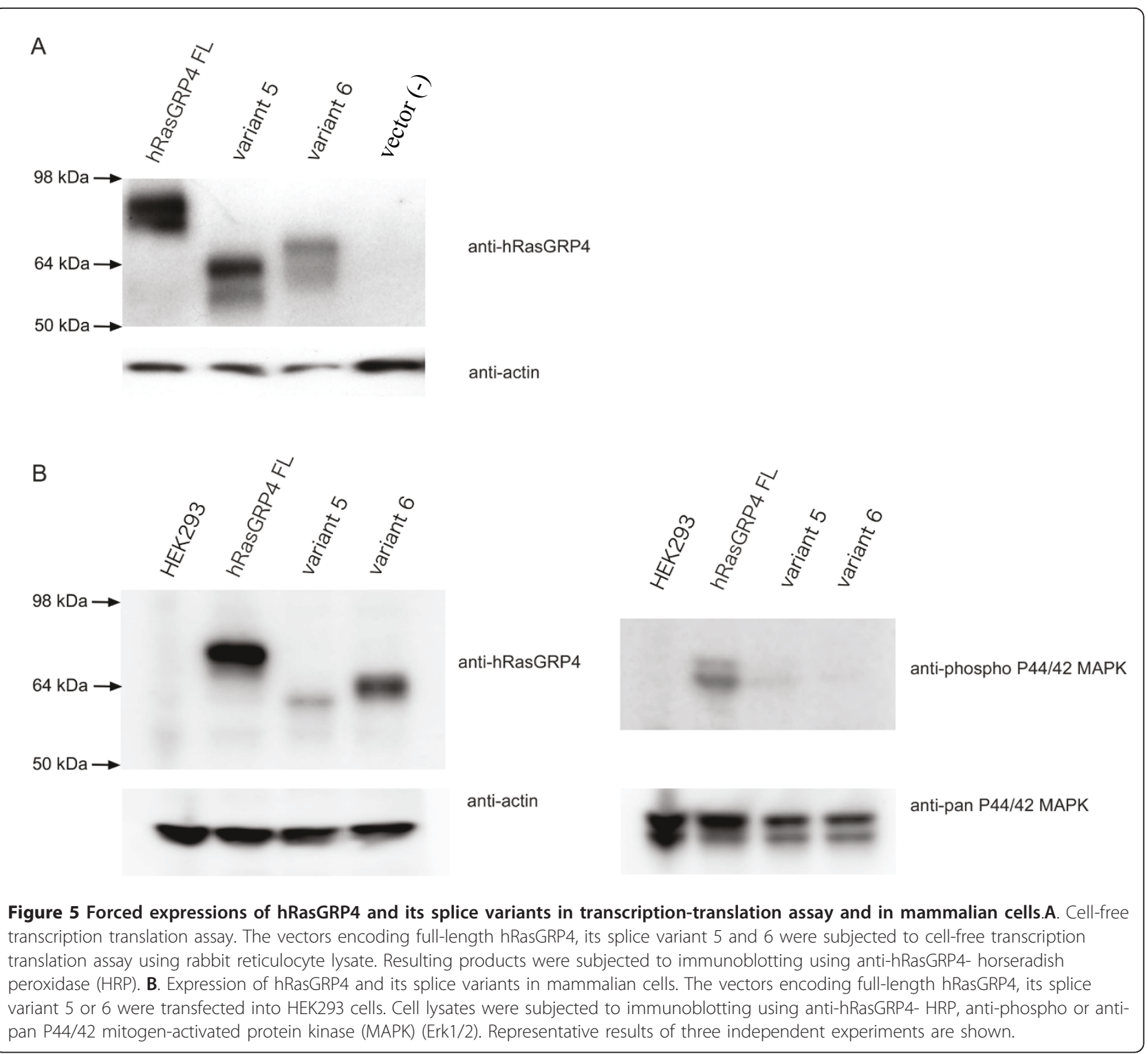

\section{Discussion}

As far as we know, this is the first report that hRasGRP4 is abundantly expressed in peripheral blood monocytes from healthy individuals both at mRNA and protein levels. This finding opens a new insight into the field of monocyte-lineage cell biology and of the diseases where this lineage cell plays a prominent role. In the latter part of the present study, we revealed dysregulation of hRasGRP4 in the PBMCs from patients with RA.

It has been concluded that the signaling protein RasGRP4 plays a prominent role in the final stages of development of mouse, rat, and human MCs $[1,5,8]$. Nevertheless, hRasGRP4 mRNA also has been detected in an undefined population of cells in mouse and human PBMCs [1]. In support of the latter data, the
hRasGRP4 transcript also has been found in the transformed leukocytes isolated from a patient with acute myeloid leukemia [4]. Although MC-committed progenitors are present in the peripheral blood, these cells are rare in number and have a $\mathrm{CD} 13^{+} / \mathrm{CD} 14^{-} / \mathrm{CD} 34$ ${ }^{+} / \mathrm{CD} 117^{+}$phenotype $[28,32]$. We, therefore, speculated that another cell population might be responsible for the presence of large amounts of RasGRP4 mRNA and protein in normal mouse and human PBMCs. We now show that the CD14 $4^{+}$myeloid cells in PBMCs express this GEF at the mRNA and protein levels (Figures 1A, C). Only $26 \mathrm{dbESTs}$ of the approximately 8.3 million human dbESTs in the GenBank-UniGene database originated from the hRasGRP4 gene. Twelve of them are from blood or bone marrow, followed by five from the 
kidney. Thus, this signaling protein normally is highly restricted in humans. More than 300,000 dbESTs have been deposited in the database that originated from the adult human lung. Although the lung contains large numbers of macrophages, only one of the lung-derived dbESTs in the database originated from the hRasGRP4 gene. In support of these dbEST data, the levels of the RasGRP4 transcript in the mouse and human lung are below detection by RNA blot analysis [1]. Because hRasGRP4 mRNA and protein are below detection in macrophage-rich organs and because human PBMCs cease expressing hRasGRP4 when they are exposed to lectins ex vivo [1], we conclude that the monocytes in PBMCs cease expressing this signaling protein when they differentiate into mature macrophages in tissues. In agreement with this conclusion, in vitro-developed human macrophages and osteoclasts contained much lower hRasGRP4 mRNA levels when evaluated by qPCR (Additional file 1/Figure S1).

Because monocytic cell lineages are indispensable initiators/effectors in inflammatory arthritis, we next focused on hRasGRP4 expression in patients with RA, then evaluated hRasGRP4 expression in PBMCs from RA patients both quantitatively and qualitatively. In the present study, we note higher levels of hRasGRP4 mRNA (Figure 2) but also a higher frequency of certain defective hRasGRP4 isoforms in the PBMCs from RA patients (Figure 3 and Table 1). In our RA patients, the expression levels of hRasGRP4 were not related to any of investigated clinical and laboratory features. Alternatively spliced isoforms of hRasGRP4 have been reported in a patient with bronchial asthma, and were designated splice variants 1, 2, and 4 [1]. Although we also detected splice variants 1 and 2 transcripts in our cohort, the frequencies of these variants were low. Instead, we identified 10 novel splice variants including 2 major variants that are preferentially expressed in RA patients (Figure 3 ). The most abundant alternatively-spliced isoform was splice variant 5 . This variant lacks exon 9 but the nucleotide sequence is kept in frame. The second abundant splice variant 6 lacks 5'-portion of exon 9 and also is in frame. This splice variant was scarcely found in healthy individuals, despite its relatively high prevalence in the patient group. In addition, splice variant 6 was related to high levels of hRasGRP4 mRNA as quantitated by qPCR. Because the probe used for qPCR theoretically recognizes the majority of the abnormal hRasGRP4 isoforms, such as splice variants 5, 6, 9, and 11 to 14 , it is likely that cells which produce large amounts of defective splice variants attempt to compensate for that problem by producing more hRasGRP4 mRNA. In support of that conclusion, a naturally occurring mRasGRP4 splice variant was identified in the MCs developed from the $\mathrm{C} 3 \mathrm{H} / \mathrm{HeJ}$ mouse strain, which are unresponsive to phorbol esters [2]. In bone marrowderived MCs developed from this mouse strain, the levels of the transcripts that encode this defective mRasGRP4 isoform were markedly higher relative to the corresponding $\mathrm{MCs}$ developed from $\mathrm{A} / \mathrm{J}$ mice that preferentially express the normal isoform of mRasGRP4. The accumulated data suggest that when a certain lineage of cells is unable to produce a normal/functional signaling protein, such cells increase their production of defective transcripts in an attempt to compensate for the defective isoform. In fact, the peripheral blood cells from RA patients fail to express a substantial amount of normal hRasGRP4 protein (Figure 4A). Although splice variant 5 lacks the entire exon 9 and splice variant 6 uses an alternative splice donor site in exon 9, we did not find any point mutation in exon 9 , splice donor site and splice acceptor site of this exon, even when the genomic DNA from a RA patient had exon 9 abnormality in all sequenced clones (data not shown). Although the reason why hRasGRP4 transcripts are defective in RA patients remains unclear, the presence of defective hRasGRP4 transcripts does not appear to be a treatment-induced phenomenon because non-treated RA patients also had a high frequency of defective hRasGRP4 cDNAs (Table 1). Other minor variants, such as splice variants 7,8 , and 11 which lack exons 1 to 3 and splice variant 13 which lacks the 5'-portion of exon 12 , do not have any premature translation termination codon. Four of the other hRasGRP4 splice variants identified in our study comprise a premature translation-termination codon. Although these transcripts are candidates for nonsense-mediated mRNA decay, if translated, these splice variants would encode truncated non-functional hRasGRP4 isoforms that have lost their DAG/phorbol ester-binding sequence. How splicing of hRasGRP4 is controlled in monocytes remains to be determined in future studies. Functional aspects of alternative splicing of CD44 caused by its polymorphism have been implicated in rheumatoid arthritis [33-35]. Although we could not clarify genetic predispositions that are related to alternative splicing of RasGRP4, we suggest that full-length RasGRP4 protein levels are regulated, at least in part, by epigenetic factors such as alternative splicing.

Because exon 9 of hRasGRP4 encodes a large portion of the conserved catalytic CDC25 box in hRasGRP4, splice variants 5 and 6 are likely to be functionally defective if translated in $\mathrm{CD} 14^{+}$cells in vivo. In fact, at least in our mammalian cell expression system, splice variant 6 was functionally defective in activating P44/42 MAPK when compared with normal hRasGRP4 (Figure $5 B)$. Although the expression of splice variant 6 at the protein level in monocytes from RA patients was unclear, lower expression of RasGRP4 and/or that of 
functionally abnormal RasGRP4 isoform might affect the development of monocytes into macrophages or osteoclasts, resulting in altered function of these cells in RA patients.

\section{Conclusions}

We clarified that hRasGRP4 is expressed in the CD14 ${ }^{+}$ monocytes in PBMCs. Because hRasGRP4 expression in monocytes is likely to be developmentally controlled, dysregulation of hRasGRP4 expression in peripheral blood monocytes may affect the cell functions of further differentiated cells such as macrophage and osteoclasts, playing pathologic roles in a subset of RA patients.

\section{Additional material}

\section{Additional file 1: Figure S1. Evaluation of hRasGRP4 transcripts in} $\mathrm{CD} 14+$ peripheral blood monocytes and in vitro cultured macrophages or osteoslasts. A. hRasGRP4 transcripts in CD14+ peripheral blood monocytes and in-vitro cultured macrophages were evaluated using real-time qPCR. The level of hRasGRP4 transcripts against GAPDH in CD14+ cells at the first experiment was defined as 1. B. hRasGRP4 transcripts in in-vitro cultured osteoclasts were measured by real-time qPCR (left panel). Expression of cathepsin K (CTSK) was measured to confirm the development of osteoclasts (right panel). In these panels, amount of target gene transcripts against GAPDH transcripts in PBMC at one experiment were defined as 1. All experiments were done in a triplicate manner and error bars indicate standard errors. OC, osteoclasts; PBMC, peripheral blood mononuclear cells; $R Q$, relative quantification.

Additional file 2: Figure S2. hRasGRP4 transcript levels and the ratios of monocytes in the peripheral blood. A. Relationship between hRasGRP4 transcript levels in PBMC from RA patients and the ratio of monocytes against the sum of monocytes plus lymphocytes. Linear relationship between Relative Quantification of hRasGRP4 in PBMC and the ratio of monocytes/(monocytes + lymphocytes) was measured using Spearman's rho analysis. B. Relationship between hRasGRP4 transcript levels in PBMC from RA patients and percentage of monocytes in the peripheral WBC. Linear relationship between Relative Quantification of hRasGRP4 in PBMC and the percentage of monocytes in WBC was measured using Spearman's rho analysis. PBMC, peripheral blood mononuclear cells; $R Q$, relative quantification.

\section{Abbreviations}

BLAST: Basic Local Alignment Search Tool; BSA: bovine serum albumin; DAB: 3,3'-diaminobenzidine tetrahydrochloride; DAS28: The Disease Activity Score in 28 joints; DAG: diacylglycerol; ESR: erythrocyte sedimentation rate; GEF: guanine nucleotide exchange factor; HRP: horseradish peroxidase; hGAPDH: human glyceraldehyde-3-phosphate dehydrogenase; IL: interleukin; MAPK: mitogen-activated protein kinase; MCs: mast cells; PM/DM: polymyositis/ dermatomyositis; PBMCs: peripheral blood mononuclear cells; PBMCs: peripheral blood mononuclear cells; RasGRP: Ras guanine nucleotide releasing protein; RA: rheumatoid arthritis; REM: Ras exchange motif; RQ: relative quantities; SLE: systemic lupus erythematosus; SS: Sjögren's syndrome; SSc: systemic sclerosis; TNF-a: tumor necrosis factor-a

\section{Acknowledgements}

We thank Dr. Richard L. Stevens (Brigham and Women's Hospital and Harvard Medical School, Boston, MA) for his helpful discussions. We also thank Ms. Ayaka Kubota (Hokkaido University Graduate School of Medicine) for technical assistance.
This work was supported by the Japanese Ministry of Health, Labor, and Welfare; Japanese Ministry of Education, Culture, Sports, Science, and Technology; Japanese Society for the Promotion of Science.

\section{Authors' contributions}

TH designed and performed experiments and performed statistical analyses. SY designed the study, performed experiments and drafted the manuscript. HK designed and performed experiments, helped with collection and acquisition of the data and drafted the manuscript. HT helped with collection and acquisition of the data and drafted the manuscript. TA and TK were involved in the interpretation and design of the study, and also drafted the manuscript. All authors contributed to the final manuscript. All authors have read and approved the manuscript for publication.

\section{Competing interests}

The authors declare that they have no competing interests.

Received: 28 March 2011 Revised: 25 May 2011

Accepted: 20 September 2011 Published: 20 September 2011

\section{References}

1. Yang Y, Li L, Wong GW, Krilis SA, Madhusudhan MS, Sali A, Stevens RL: RasGRP4, a new mast cell-restricted Ras guanine nucleotide-releasing protein with calcium- and diacylglycerol-binding motifs. Identification of defective variants of this signaling protein in asthma, mastocytosis, and mast cell leukemia patients and demonstration of the importance of RasGRP4 in mast cell development and function. J Biol Chem 2002, 277:25756-25774.

2. $\quad L i$ L, Yang $Y$, Stevens RL: Cloning of rat Ras guanine nucleotide releasing protein 4 , and evaluation of its expression in rat mast cells and their bone marrow progenitors. Mol Immunol 2002, 38:1283-1288.

3. Li L, Yang Y, Wong GW, Stevens RL: Mast cells in airway hyporesponsive $\mathrm{C} 3 \mathrm{H} / \mathrm{HeJ}$ mice express a unique isoform of the signaling protein Ras guanine nucleotide releasing protein 4 that is unresponsive to diacylglycerol and phorbol esters. J Immunol 2003, 171:390-397.

4. Reuther GW, Lambert QT, Rebhun JF, Caligiuri MA, Quilliam LA, Der CJ: RasGRP4 is a novel Ras activator isolated from acute myeloid leukemia. J Biol Chem 2002, 277:30508-30514.

5. Li L, Yang Y, Stevens RL: RasGRP4 regulates the expression of prostaglandin D2 in human and rat mast cell lines. J Biol Chem 2003, 278:4725-4729.

6. Layer K, Lin G, Nencioni A, Hu W, Schmucker A, Antov AN, Li X, Takamatsu S, Chevassut T, Dower NA, Stang SL, Beier D, Buhlmann J, Bronson RT, Elkon KB, Stone JC, Van Parijs L, Lim B: Autoimmunity as the consequence of a spontaneous mutation in Rasgrp1. Immunity 2003, 19:243-255.

7. Yasuda S, Stevens RL, Terada T, Takeda M, Hashimoto T, Fukae J, Horita T, Kataoka $H$, Atsumi T, Koike T: Defective expression of Ras guanyl nucleotide-releasing protein 1 in a subset of patients with systemic lupus erythematosus. I Immunol 2007, 179:4890-4900.

8. Katsoulotos GP, Qi M, Qi JC, Tanaka K, Hughes WE, Molloy TJ, Adachi R, Stevens RL, Krilis SA: The diacylglycerol-dependent translocation of ras guanine nucleotide-releasing protein 4 inside a human mast cell line results in substantial phenotypic changes, including expression of interleukin 13 receptor alpha2. J Biol Chem 2008, 283:1610-1621.

9. Lewis RA, Soter NA, Diamond PT, Austen KF, Oates JA, Roberts LJ: Prostaglandin D2 generation after activation of rat and human mast cells with anti-IgE. J Immunol 1982, 129:1627-1631.

10. Kanaoka Y, Ago H, Inagaki E, Nanayama T, Miyano M, Kikuno R, Fujii Y, Eguchi N, Toh H, Urade Y, Hayaushi O: Cloning and crystal structure of hematopoietic prostaglandin D synthase. Cell 1997, 90:1085-1095.

11. Kochi Y, Suzuki A, Yamada R, Yamamoto K: Ethnogenetic heterogeneity of rheumatoid arthritis-implications for pathogenesis. Nat Rev Rheumatol 2010, 6:290-295.

12. Tobon GJ, Youinou P, Saraux A: The environment, geo-epidemiology, and autoimmune disease: rheumatoid arthritis. J Autoimmun 2010, 35:10-14.

13. Crisp AJ, Chapman CM, Kirkham SE, Schiller AL, Krane SM: Articular mastocytosis in rheumatoid arthritis. Arthritis Rheum 1984, 27:845-851.

14. Bromley M, Woolley DE: Histopathology of the rheumatoid lesion. Identification of cell types at sites of cartilage erosion. Arthritis Rheum 1984, 27:857-863. 
15. Tetlow LC, Woolley DE: Mast cells, cytokines, and metalloproteinases at the rheumatoid lesion: dual immunolocalisation studies. Ann Rheum Dis 1995, 54:896-903.

16. van den Broek MF, van den Berg WB, van de Putte LB: The role of mast cells in antigen induced arthritis in mice. J Rheumatol 1988, 15:544-551.

17. Lee DM, Friend DS, Gurish MF, Benoist C, Mathis D, Brenner MB: Mast cells: a cellular link between autoantibodies and inflammatory arthritis. Science 2002, 297:1689-1692.

18. Corr $M$, Crain B: The role of FcgammaR signaling in the $K / B \times N$ serum transfer model of arthritis. J Immunol 2002, 169:6604-6609.

19. McNeil HP, Shin K, Campbell IK, Wicks IP, Adachi R, Lee DM, Stevens RL: The mouse mast cell-restricted tetramer-forming tryptases mouse mast cell protease 6 and mouse mast cell protease 7 are critical mediators in inflammatory arthritis. Arthritis Rheum 2008, 58:2338-2346.

20. Shin K, Nigrovic PA, Crish J, Boilard E, McNeil HP, Larabee KS, Adachi R, Gurish MF, Gobezie R, Stevens RL, Lee DM: Mast cells contribute to autoimmune inflammatory arthritis via their tryptase/heparin complexes. J Immunol 2009, 182:647-656.

21. Valent $P$, Ashman LK, Hinterberger W, Eckersberger F, Majdic O, Lechner $K$, Bettelheim P: Mast cell typing: demonstration of a distinct hematopoietic cell type and evidence for immunophenotypic relationship to mononuclear phagocytes. Blood 1989, 73:1778-1785.

22. Saito H, Ebisawa M, Tachimoto H, Shichijo M, Fukagawa K, Matsumoto K, likura Y, Awaji T, Tsujimoto G, Yanagida M, Uzumaki H, Takahashi G, Tsuji K, Nakahata T: Selective growth of human mast cells induced by Steel factor, IL-6, and prostaglandin E2 from cord blood mononuclear cells. J Immunol 1996, 157:343-350.

23. Szekanecz Z, Koch AE: Macrophages and their products in rheumatoid arthritis. Curr Opin Rheumatol 2007, 19:289-295.

24. Lutzky V, Hannawi S, Thomas R: Cells of the synovium in rheumatoid arthritis. Dendritic cells. Arthritis Res Ther 2007, 9:219.

25. Schett G: Cells of the synovium in rheumatoid arthritis. Osteoclasts. Arthritis Res Ther 2007, 9:203.

26. Arnett FC, Edworthy SM, Bloch DA, McShane DJ, Fries JF, Cooper NS, Healey LA, Kaplan SR, Liang MH, Luthra HS, Medsger TA Jr, Mitchell DM, Neustadt DH, Pinals JG, Schaller JG, Sharp JT, Wilder RL, Hunder GG: The American Rheumatism Association 1987 revised criteria for the classification of rheumatoid arthritis. Arthritis Rheum 1988, 31:315-324.

27. Prevoo ML, van 't Hof MA, Kuper HH, van Leeuwen MA, van de Putte LB, van Riel PL: Modified disease activity scores that include twenty-eightjoint counts. Development and validation in a prospective longitudinal study of patients with rheumatoid arthritis. Arthritis Rheum 1995, 38:44-48.

28. Kirshenbaum AS, Goff JP, Semere T, Foster B, Scott LM, Metcalfe DD: Demonstration that human mast cells arise from a progenitor cell population that is CD34(+), c-kit(+), and expresses aminopeptidase N (CD13). Blood 1999, 94:2333-2342.

29. Akagawa KS: Functional heterogeneity of colony-stimulating factorinduced human monocyte-derived macrophages. Int J Hematol 2002, 76:27-34.

30. Littlewood-Evans A, Kokubo T, Ishibashi O, Inaoka T, Wlodarski B, Gallagher JA, Bilbe G: Localization of cathepsin $\mathrm{K}$ in human osteoclasts by in situ hybridization and immunohistochemistry. Bone 1997, 20:81-86.

31. Image Processing and Analysis in Java. [http://rsbweb.nih.gov/ij/].

32. Wang XS, Yip KH, Sam SW, Lau HY: Buffy coat preparation is a convenient source of progenitors for culturing mature human mast cells. J Immunol Methods 2006, 309:69-74

33. Wibulswas A, Croft D, Pitsillides AA, Bacarese-Hamilton I, Mclntyre P, Genot E, Kramer IM: Influence of epitopes CD44v3 and CD44v6 in the invasive behavior of fibroblast-like synoviocytes derived from rheumatoid arthritic joints. Arthritis Rheum 2002, 46:2059-2064.

34. Golan I, Nedvetzki S, Eshkar-Sebban L, Levartovsky D, Elkayam O, Caspi D, Aamar S, Amital H, Rubinow A, Naor D: Expression of extra trinucleotide in CD44 variant of rheumatoid arthritis patients allows generation of disease-specific monoclonal antibody. J Autoimmun 2007, 28:99-113.

35. Naor D, Nedvetzki S: CD44 in rheumatoid arthritis. Arthritis Res Ther 2003, 5:105-115

doi:10.1186/ar3470

Cite this article as: Hashimoto et al:: Aberrant splicing of the hRasGRP4

transcript and decreased levels of this signaling protein in the peripheral blood mononuclear cells in a subset of patients with rheumatoid arthritis. Arthritis Research \& Therapy 2011 13:R154.

\section{Submit your next manuscript to BioMed Central and take full advantage of:}

- Convenient online submission

- Thorough peer review

- No space constraints or color figure charges

- Immediate publication on acceptance

- Inclusion in PubMed, CAS, Scopus and Google Scholar

- Research which is freely available for redistribution

Submit your manuscript at www.biomedcentral.com/submit
Biomed Central 